\title{
Interactive comment on "Impact of frozen soil processes on soil thermal characteristics at seasonal to decadal scales over the Tibetan Plateau and North China" by Qian Li et al.
}

\section{Anonymous Referee \#2}

Received and published: 13 December 2020

The soil freezing and thawing processes are vital for land surface models because they influence both the soil thermal and hydrological variables and modified the land surface memory which play important roles in determining land-atmosphere interactions. However, current land surface models solve the freezing-thawing cycle by using a separated method, where soil temperature is firstly calculated and then soil freezing and thawing processes are adjusted. Li et al., coupled a physically more realistic and computationally more stable and efficient frozen soil module (FSM) into a land surface model the third-generation Simplified Simple Biosphere model (SSiB3-FSM), and evaluated the new model over the Tibetan Plateau and northern China systematically. They also investigated the influences of soil freezing-thawing cycle on the soil temperature

Printer-friendly version

Discussion paper 
profile, maximum frozen soil depth and soil memory. Generally, the work is important for the land model community and deepens our understanding of the influences of soil freezing-thawing processes. However, some minor revisions are still needed before its publication. 1.The author used the GHCN-CAMS product to evaluate the T2m simulations of SSiB3-FSM. I am confused that whether the temperature forcing from the Princeton is already the T2m? If so, how do you process the temperature forcings as land surface models usually need the forcings at the lowest level of atmosphere model? 2.The soil layer depth of the SSiB3-FSM is $3 \mathrm{~m}$ and the soil temperature stations over TP are all seasonally frozen ground whose maximum frozen depth is shallower than $3 \mathrm{~m}$. However, for some regions such as the western TP, the maximum frozen depth will be deeper than $3 \mathrm{~m}$. Will this influence the results in section 4.2.1 which seems to use the whole TP as study region. 3.In section 4.2.2, the author said that land memory in TP is not given because it has been well studied by previous works. While I still suggest to give the results in the supporting information to improve the good performance of SSiB3-FSM. 4.The author compared the observed and simulated normalized maximum frozen depth in section 4.4 , and I wonder why do you directly compare the original values? 5.In section 4.1.1 and Table 1, although the author give the evaluation results of T2m at global scale, the detailed results over TP and NC are still needed. 6.The subsections in 4.1 should be revised. Change the "(2) Soil temperature profile in the TP" to "4.1.2 ...", the "(3) Soil ..." to "4.1.3 ..."

Interactive comment on Hydrol. Earth Syst. Sci. Discuss., https://doi.org/10.5194/hess-2020$578,2020$. 